\title{
The interplay between inflammation, physical activity and metabolic syndrome in a remote male geriatric community in Southern Taiwan: the Tianliao Old People (TOP) study 03
}

Chia-Ling Chang ${ }^{1}$, Po-Tseng Lee ${ }^{2,3,4}$, Wei-Ting Chang ${ }^{2,3}$, Chin-Sung Chang ${ }^{3,5}$, Jyh-Hong Chen ${ }^{2}$, Liang-Miin Tsai ${ }^{2}$, Chih-Hsing $\mathrm{Wu}^{5}$ and Ping-Yen Liu $2,3^{*}$

\begin{abstract}
Background: Both physical activity and inflammation are important in the pathophysiology of metabolic syndrome (MetS). Our study aim is to explore their associations in an elderly male ( $\geq 65$ years old) cohort.

Methods: We enrolled 309 elderly male residents (mean age: $74.4 \pm 6.0$ years) in a remote southern Taiwan community. The physical activity was recorded by a standard questionnaire. A high-sensitivity C-reactive protein (hsCRP) level $>3.0 \mathrm{mg} / \mathrm{L}$ indicated a high inflammatory status.

Results: The total prevalence rate of MetS was $27.8 \%$ in this male geriatric cohort. Median hsCRP levels were significantly higher in the MetS group (1.60 $\pm 0.7 \mathrm{vs} .1 .0 \pm 0.3 \mathrm{mg} / \mathrm{L}, p<0.01$ ), and the risk of elevated hsCRP increased with escalating MetS components ( $p$ for trend $<0.001$ ). The non-MetS group had higher amount of median weekly physical activity (183.1 \pm 19.0 vs. $173.5 \pm 10.6 \mathrm{MET}$-hr/week, $p=0.029)$, which was also higher among those with lower hsCRP levels (186.1 \pm 14.1 vs. $167.8 \pm 38.5 \mathrm{MET}$-hr/week, $p=0.013$ ). Multivariate analysis showed that higher body mass index (ORs: 1.527, 95\% Cl: 1.319-1.768, $p<0.01$ ) insulin (OR: 1.128, 95\% Cl: 1.045-1.218, $p<0.01$ ) and physical activity (ORs: 0.997, 95\% IC: 0.994-0.999, $p<0.05)$ were independent predictors of MetS, but not hsCRP level $(p>0.05)$.
\end{abstract}

Conclusions: Reduced physical activity was one major pathophysiological MetS factor in our Asian geriatric participants.

Keywords: Metabolic syndrome, Inflammation, Physical activity, Geriatric

\section{Introduction}

In 1988, the concept of metabolic syndrome (MetS), a cluster of metabolic factors, was proposed [1]. MetS is not a single disease, but a syndrome that causes physiological abnormalities such as abnormal vascular function, impaired glucose tolerance, and abnormal coagulation factors, all of which increase the risk of poor outcomes for diabetes mellitus (DM) and cardiovascular disorders [2,3]. Obesity $[4,5]$, physical activity [6-8], and inflammation $[9,10]$ may be the major pathophysiological factors of MetS.

\footnotetext{
* Correspondence: larry@mail.ncku.edu.tw

${ }^{2}$ Division of Cardiology, Internal Medicine, National Cheng Kung University Hospital, Tainan, Taiwan

${ }^{3}$ Institute of Clinical Medicine, National Cheng Kung University, Tainan, Taiwan

Full list of author information is available at the end of the article
}

It is still unclear that the association is true in the elderly ( $\geq 65$ years old). We thus explored the association between MetS, physical activity, and low-grade inflammation markers, presented by high-sensitivity $\mathrm{C}$-reactive protein (hsCRP) concentrations in elderly men in a remote area of southern Taiwan.

hsCRP is one indicator of inflammation. When developing inflammation, plasma hsCRP level elevates abruptly; therefore, it is referred to as a biomarker of low-grade inflammation. In addition, adipose tissue releases many inflammatory cytokines, such as interleukin- 6 and tumor necrosis factor- $\alpha$, which elevate plasma hsCRP levels [9]. Aging process also elevates plasma hsCRP levels $[9,11]$. Higher plasma hsCRP levels are associated with an increased the risk of DM [10,12-15] and cardiovascular

\section{Ciomed Central}


disease $[10,11,13,16-18]$. Plasma hsCRP levels are also related to MetS $[9,10,13,15,19,20]$ and the components of MetS [19].

Lower physical activity in healthy young adults is associated with abnormal metabolic consequences such as decreased insulin sensitivity and increased abdominal fat [21], which links many components of MetS. Inflammation also induces insulin resistance [21]. A higher-level physical activity was reported to be associated with decrease plasma hsCRP level [22], which is an indicator of lower inflammatory status. To our best knowledge, it remained unclear whether the association between hsCRP and the strength of daily physical activity regarding MetS is true in the elderly population. We thus hypothesized that though the elderly population might have average higher levels of lower-grade inflammation status indicated by hsCRP levels, higher physical activity could be related to less abnormal metabolic profiles in an aging community survey.

\section{Methods}

\section{Study population and data collection}

According to the public health database in 2010 from the National Health Research Institute in Taiwan, Tianliao was the third-fastest aging village in Taiwan and the highest percentage of elderly residents in southern Taiwan. In addition, the village had only limited medical resources. According to the August 2010 census [23], there were 8,421 people (4,583 men; 3,658 women) in the village and the rate of people older than 65 years of age was $10.5 \%$ in Taiwan, but $24.1 \%$ in Tianliao. In addition, based on the aging index, defined by equation as the ratio of ([(population $\geq 65$ years old)/ (population $\leq 14$ years old) $\times 100$ ), was as high as $299 \%$, Tianliao could be classified as a "severely aging village".

The study surveyed voluntary men residents over $\geq$ 65 years old in this remote aging community in July and August 2010. According to the census, there were 1,012 men $\geq 65$ years old in Tianliao. Those who wished to participate in the study were called to the nearest public health examination station via the public address broadcasting system or door-to-door invitation. Except for 62 men who were disabled and 269 men who did not live there, only 681 of those recruited were eligible, 414 men agreed to participate in our study. The response rate was $60.8 \%$ and the statistical power was 0.80 . There were no significant differences in background or age distribution between participants and non-participants. Each participant underwent a structured questionnaire interview and a blood test. The study protocol was approved by the National Cheng Kung University ethics committee (IRB no: ER-99-111), and all participants signed an informed consent form before the study began.

\section{Questionnaire design}

A standardized face-to-face interview based on structured questionnaires was conducted by well-trained interviewers.
The questionnaire asked about participant's medical history, as well as physical activity.

\section{Physical activity}

Self-reported physical activity in usual seven days was calculated through the Taiwanese version of short form of international physical activity questionnaire (IPAQ). The total hours over the last seven days spent on vigorous and moderate-intensity physical activity, walking and sitting was obtained through IPAQ. The amount of physical activity was converted to metabolic equivalent task hours per week (MET-hr/week) according to the IPQA scoring protocol [24]. The formula we applied for the average MET score were calculated from each type of physical activity: vigorous physical activity $=8.0 \mathrm{METs}$, moderate physical activity $=4.0$ METs, walking $=3.3$ METs, sitting $=1$ MET, and total physical activity $=$ sum of vigorous + moderate + walking + sitting MET-hr/week scores.

\section{Definition of MetS and DM}

MetS was defined, based upon the National Cholesterol Education Program Adult Treatment Panel III (NCEPATPIII) with criteria modified in 2005 for Asian Americans [25], as presenting 3 or more of the following components: (1) waist circumference $\geq 90 \mathrm{~cm}$ for men; (2) triglycerides $\geq$ $150 \mathrm{mg} / \mathrm{dL}$; (3) HDL-C < $40 \mathrm{mg} / \mathrm{dL}$ for men; (4) blood pressure $\geq 130 / 85 \mathrm{mmHg}$ or current use of antihypertensive medication; (5) fasting glucose $\geq 100 \mathrm{mg} / \mathrm{dL}$. DM was defined according to the American Diabetes Association 2010 diagnostic criteria [26] and the medical history reported by each participant.

\section{Laboratory methods}

After the participants had fasted for at least 8 hours, peripheral blood samples were collected from them and centrifuged at 3,000 rpm for $15 \mathrm{~min}$ at $4^{\circ} \mathrm{C}$. The samples were frozen and then sent to a central laboratory for analysis. Measurement of insulin, fasting glucose, hemoglobin A1c $\left(\mathrm{HbA1}_{\mathrm{C}}\right)$, total cholesterol, high-density lipoprotein (HDL-C), low-density lipoprotein (LDL-C), and triglyceride levels were described by previous study [8]. Level of hsCRP was measured using a particle-enhanced turbidimetric assay. In this study, we used the cut-off value of hsCRP to predict high level of inflammation by the criteria set by the American Heart Association [27], which defines a plasma hsCRP level $>3.0 \mathrm{mg} / \mathrm{L}$ to be as a high hsCRP level.

\section{Statistical analysis}

Data management and statistical analyses were performed with SPSS 12.0. Continuous variables with a normal distribution (fasting glucose, total cholesterol, HDL-C, LDL-C, waist circumference, height, weight, body fat, and body mass index (BMI)) were expressed as means \pm standard deviation (SD). Continuous variables with a non-normal 
distribution (age, hsCRP level, insulin, triglycerides, components of MetS, physical activity, and quantity of alcohol consumed) were expressed as means \pm standard error (SE). Categorical variables were reported as numbers and percentages. Normality was tested using the Kolmogorov-Smirnov test. Continuous variables were compared using a Student's $t$ test for normally distributed values; otherwise, a non-parametric Mann-Whitney $U$ test was used. Comparisons between categorical variables were made using a $\chi^{2}$ test. Spearman partial correlation coefficients of hsCRP and components of MetS were calculated. Odds ratios (ORs) and 95\% confidence intervals (CI) were assessed using logistic regression. Statistical tests were 2-sided; significance was set at $p<0.05$.

\section{Results}

We enrolled 309 participants (all gentlemen; mean age: $74.4 \pm 6.0$ years; range: $65-98$ years) for analysis. Excluded were 9 with various treatment strategies and 96 with a history of DM. The prevalence of high blood pressure was $76.7 \%$; the mean waist circumference was $85.6 \pm 11.0 \mathrm{~cm}$, HDL-C was $47.8 \pm 11.6 \mathrm{mg} / \mathrm{dL}$, and fasting glucose was $95.9 \pm 9.3 \mathrm{mg} / \mathrm{dL}$; and the median hsCRP was $1.3 \pm 0.3 \mathrm{mg} / \mathrm{L}$, weekly physical activity was $179.53 \pm 14.14 \mathrm{MET}$-hr/week and triglyceride level was $97.0 \pm 3.5 \mathrm{mg} / \mathrm{dL}$. Table 1 showed the clinical characteristics stratified by MetS among the elderly male population.

\section{The prevalence and components of MetS in Asian geriatrics} According to the 2005 NCEP-ATPIII definition of MetS, the prevalence of MetS was $36.4 \%$. Excluding DM, the prevalence was $27.8 \%$, which was lower than the previously reported data for Caucasians [28]. Because MetS was composed of multiple components and mostly defined from younger aged adult populations, we were interested in which component played the most dominant roles in this geriatric community. The most common diagnostic factor for MetS was hypertension, followed by a large waist circumference, low HDL-C, high fasting glucose, and high triglycerides (Table 1).

\section{The associations between MetS, inflammation and physical activity}

Among novel inflammatory biomarkers, hsCRP was measured in this Asian geriatric cohort to indicate the individual inflammation status. The median plasma hsCRP level was $1.3 \pm 0.3 \mathrm{mg} / \mathrm{L}$ in the total population, and was significantly higher in the MetS sub-group than non-MetS sub-group $(1.6 \pm 0.7$ vs. $1.0 \pm 0.3 \mathrm{mg} / \mathrm{L}, p<0.01)$ (Figure $1 \mathrm{~A})$. Furthermore, the risk of elevated hsCRP increased with escalating MetS components ( $p$ for trend $<0.001$ ). The risk of a diagnosis of MetS was significantly higher for those with the highest when compared with those who having the lowest quartile of hsCRP levels (ORs: 2.767, 95\% CI: 1.315-5.821,
Table 1 Clinical characteristics: comparison between non-MetS and MetS groups

\begin{tabular}{|c|c|c|}
\hline Variation & Non-MetS $(n=223)$ & MetS $(n=86)$ \\
\hline Age (years)* & $74 \pm 0.4$ & $74 \pm 0.6$ \\
\hline $\mathrm{hsCRP}(\mathrm{mg} / \mathrm{L})^{*}$ & $1.0 \pm 0.3$ & $1.6 \pm 0.7^{* *}$ \\
\hline \multicolumn{3}{|l|}{ ATP III MetS criteria (\%) } \\
\hline Hypertension & 71.7 & $89.5^{* *}$ \\
\hline Increased waist & 18.8 & $74.4^{* * *}$ \\
\hline Low HDL-C & 9.9 & $70.9^{* * *}$ \\
\hline Hyperglycemia & 21.5 & $59.3^{* * *}$ \\
\hline High triglyceride & 3.6 & $51.2^{* * *}$ \\
\hline Fasting glucose (mg/dL) & $93.7 \pm 7.7$ & $101.5 \pm 10.6^{* * *}$ \\
\hline Insulin $(\mathrm{ulU} / \mathrm{mL})^{*}$ & $4.8 \pm 0.3$ & $9.4 \pm 1.4^{* * *}$ \\
\hline Cholesterol (mg/dL) & $194.5 \pm 36.2$ & $194.1 \pm 33.7$ \\
\hline Triglycerides $(\mathrm{mg} / \mathrm{dL})^{*}$ & $84.0 \pm 2.1$ & $151 \pm 9.0^{* * *}$ \\
\hline $\mathrm{LDL}-\mathrm{C}(\mathrm{mg} / \mathrm{dL})$ & $124.8 \pm 31.0$ & $123.0 \pm 31.7$ \\
\hline $\mathrm{HDL}-\mathrm{C}(\mathrm{mg} / \mathrm{dL})$ & $51.4 \pm 11.1$ & $38.5 \pm 6.7^{* * *}$ \\
\hline Waist (cm) & $82.2 \pm 10.3$ & $94.2 \pm 7.6^{* * *}$ \\
\hline Height (cm) & $160.9 \pm 5.9$ & $161.8 \pm 5.4$ \\
\hline Weight (kg) & $59.5 \pm 8.2$ & $69.4 \pm 8.3^{* * *}$ \\
\hline $\mathrm{BMI}\left(\mathrm{kg} / \mathrm{m}^{2}\right)$ & $23.0 \pm 2.7$ & $26.5 \pm 2.8^{* * *}$ \\
\hline Body fat* & $18.8 \pm 6.2$ & $23.3 \pm 0.6^{* * *}$ \\
\hline Physical activity(MET-hr/week) & $183.1 \pm 19.0$ & $173.5 \pm 10.6^{*}$ \\
\hline MetSC* & $1 \pm 0.05$ & $3 \pm 0.07^{* * *}$ \\
\hline Smoke, current & 17 & 17.4 \\
\hline Liver disease (\%) & 3.6 & 4.7 \\
\hline Stroke (\%) & 3.1 & $10.5^{*}$ \\
\hline Heart disease (\%) & 13.0 & 18.6 \\
\hline Arrhythmia (\%) & 2.2 & 3.5 \\
\hline Cardiac catheterization (\%) & 4.0 & 4.7 \\
\hline
\end{tabular}

1. Continuous variables with normal distribution are mean \pm standard deviation (SD) and with non-normal distribution (variation*) are median \pm standard error (SE). Categorical variables are reported as numbers and percentages, as indicated. 2. Continuous variables with normal distribution were tested using Student's $t$ test; otherwise, Mann-Whitney $\mathrm{U}$ test was used. Comparisons between categorical variables were made using a $x^{2}$ test. ${ }^{*} p<0.05 ;{ }^{* *} p<0.01$; *** $p<0.001$. Abbreviations: ATP III = Adult Treatment Panel III; BMI = body mass index; $\mathrm{HDL}-\mathrm{C}=$ high-density lipoprotein; hsCRP = high-sensitivity C-reactive protein; LDL-C = low-density lipoprotein; MetS = metabolic syndrome.

$p<0.01)$. All these evidence support the pathophysiologic correlation between geriatric MetS and inflammation.

The amount of physical activity recorded from our individual questionnaire was compared and analyzed between different metabolic components as well as the inflammatory biomarkers. The non-MetS group had higher amount of median weekly physical activity (non-MetS vs. MetS group: $183.1 \pm 19.0$ vs. $173.5 \pm 10.6$ MET-hr/week, $p=0.029$ ) (Figure 1B). The physical activity amount was also higher among those with lower hsCRP levels (higher vs. lower hsCRP: $167.8 \pm 38.5$ vs. $186.1 \pm 14.1$ MET-hr/week, $p=0.013$ ) (Figure $1 \mathrm{C}$ ). This implied that 


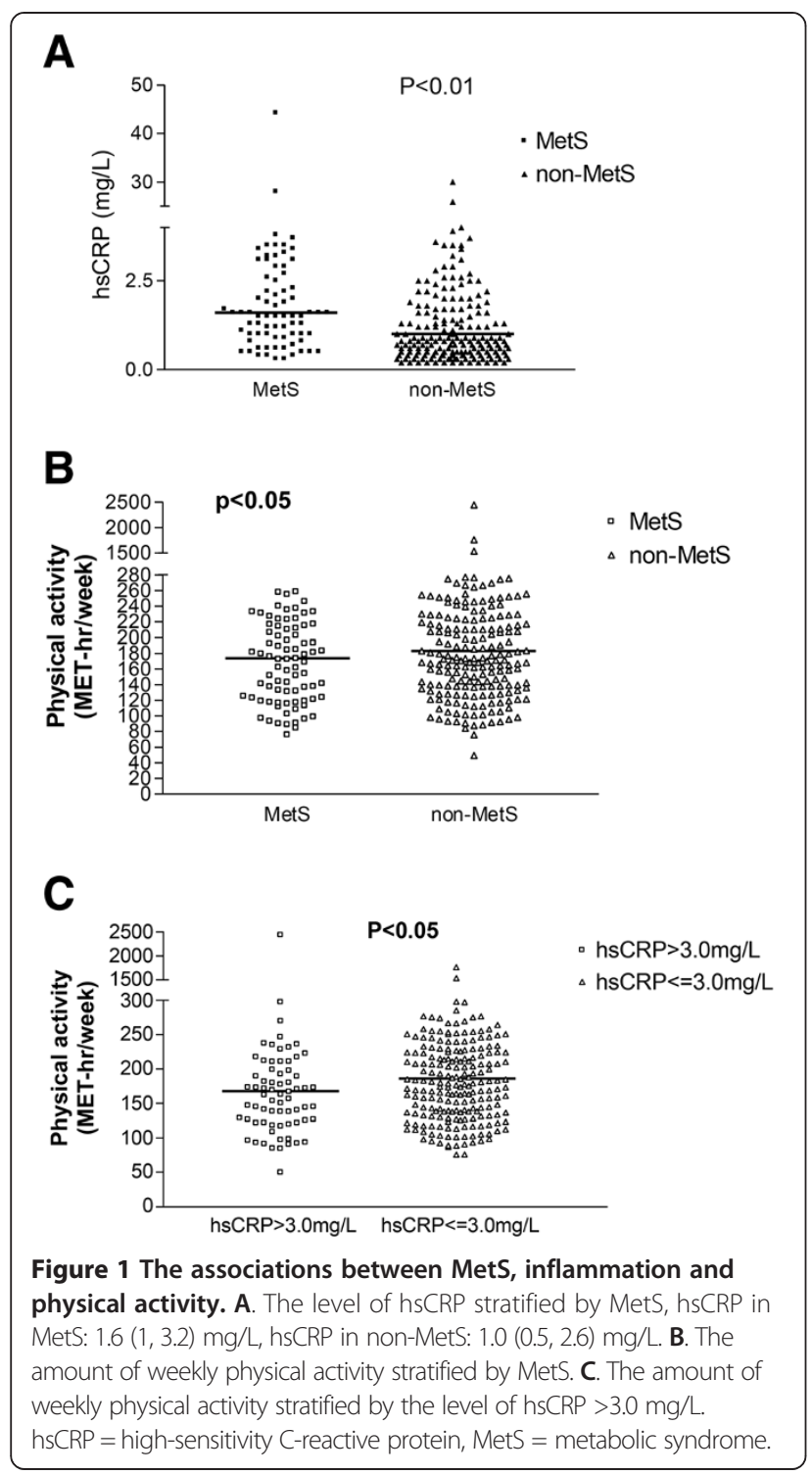

physical activity was associated with MetS and the inflammation status indicated by the hsCRP level.

\section{Individual MetS components and inflammation}

To understand the role of plasma hsCRP level in MetS, the participants with MetS were post hoc subdivided into two groups according to their individual MetS components (Figure 2). We used the ORs for the highest hsCRP level from the entire study population with MetS as the standard baseline to analyze the variation between the ORs from those with and without individual MetS risk components. The variation in ORs from MetS participants with-orwithout a low HDL-C level was the greatest of the five traditional risk components of MetS. These data indicated that HDL-C level might have the greatest interaction with the plasma hsCRP level. In addition, multivariate analysis

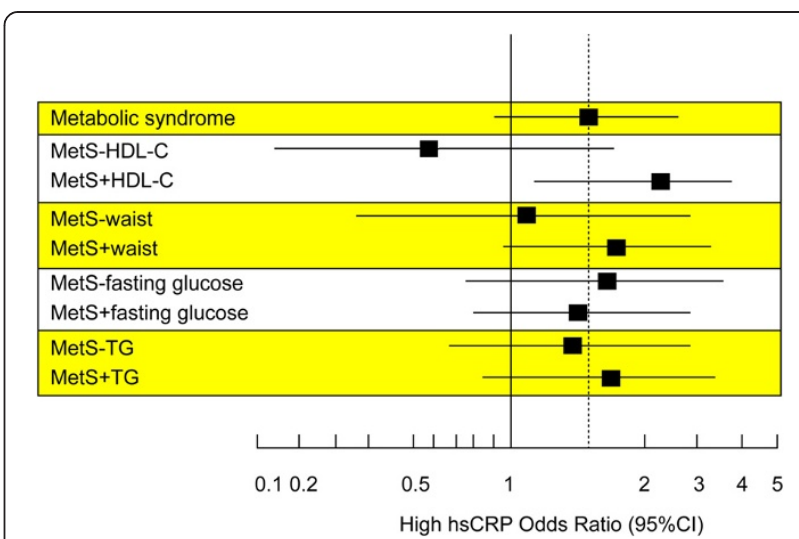

Figure 2 Interaction between individual MetS components and inflammation. Odds ratio ( $95 \% \mathrm{Cl})$ for high hsCRP plasma levels with MetS, according to absence (-) or presence (+) of single MetS components. HDL-C = high-density lipoprotein, hsCRP = high-sensitivity C-reactive protein, MetS = metabolic syndrome, $\mathrm{TG}=$ triglycerides, $\mathrm{Cl}=$ confidence interval.

with adjustment for physical activity showed that a low HDL-C level was the strongest predictor for higher hsCRP in MetS among all risk components (ORs: 6.318, 95\% CI: 1.563-25.536, $p<0.05$ ) (Table 2).

\section{Individual MetS components and physical activity}

Since the physical activity was associated with the prevalence rate of MetS, we also analyzed its association with individual MetS components (Figure 3). We found that either those with lower waist circumference (higher vs. lower: $165.9 \pm 24.8$ vs. $185.5 \pm 17.2 \mathrm{MET}$-hr/week, $p=0.048$ ) or higher levels of HDL-C (higher vs. lower: $186.1 \pm 18.7$ vs. $170.6 \pm 11.3 \mathrm{MET}-\mathrm{hr} /$ week, $p=0.003$ ) had a higher median weekly physical activity. But this phenomenon was not significant regarding hypertension, glucose control or triglyceride level.

\section{Multiple risk factors analysis}

Multivariate analysis showed that BMI (ORs: 1.527, 95\% CI: 1.319-1.768, $p<0.01$ ), insulin (OR: 1.128, 95\% CI: 1.045 $1.218, p<0.01$ ) and physical activity (ORs: $0.997,95 \%$ IC: $0.994-0.999, p<0.05$ ), rather than the level of hsCRP (ORs: 1.022, 95\% CI: 0.965-1.082, $p>0.05$ ) were independent predictors of MetS (Table 3).

\section{Discussion}

Among this elderly community survey, we found an interesting interplay between inflammation and physical activity for the development of MetS. In this geriatric cohort, only the physical activity amount plays the most important role in the pathophysiology of elderly MetS. Though the inflammation may interact with individual risk component in MetS, it remains as a phenomenon associated with the average weekly activity per se. 
Table 2 Individual MetS component and physical activity associated with high hsCRP plasma levels in MetS

\begin{tabular}{llll}
\hline & ORs & $\mathbf{9 5 \% ~ C l}$ & $\boldsymbol{P}$ \\
\hline HDL-C & 6.318 & $1.563-25.536$ & 0.010 \\
Waist & 3.031 & $0.898-10.235$ & 0.074 \\
TG & 1.512 & $0.518-4.412$ & 0.449 \\
Fasting glucose & 1.251 & $0.424-3.692$ & 0.685 \\
Hypertension & 1.139 & $0.215-6.039$ & 0.878 \\
Physical activity & 1.000 & $0.995-1.005$ & 0.967 \\
\hline
\end{tabular}

Abbreviations: $\mathrm{hs} C \mathrm{RP}=$ high-sensitivity C-reactive protein; MetS = metabolic syndrome; $\mathrm{ORs}=$ odds ratios; $\mathrm{Cl}=$ confidence intervals; $\mathrm{HDL}-\mathrm{C}=$ high-density lipoprotein; TG = triglyceride.

\section{Association between physical activity and hsCRP level}

In this special cohort, we surveyed a remote community with a low level of economic development and low socioeconomic status in southern Taiwan. Most of the residents were farmers whose non-MetS population engaged in substantially more average weekly physical activities than the MetS population. At the same time, they also had lower hsCRP levels, which were generally considered as an indicator of lower inflammatory status.

Previous report showed that physical activity is an effective way to increased human HDL-C $[29,30]$, which was also associated with a higher-level of physical activity as well as hsCRP [11,31]. Indeed, Dai et al. [29] observed another Taiwanese population cohort and found that a high level of physical activity was associated with increased HDL-C levels. Geffken et al. [22] also reported that a high level physical activity might decrease plasma hsCRP level. These data support the notion that physical activity is related to inflammation status, and in our cohort, more physically active participants had lower-grade inflammation biomarkers, i.e., hsCRP levels. Instead of hsCRP, the only remained multivariable predictor for MetS was physical activity amount. We thus hypothesized that inflammation

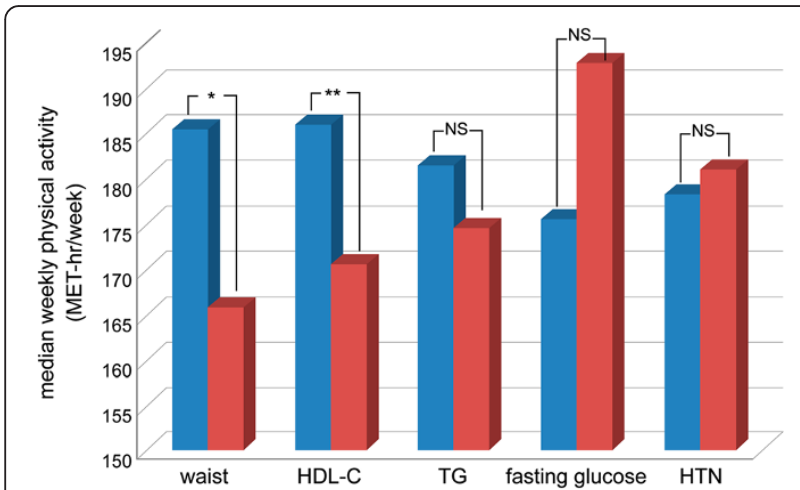

Figure 3 The median of weekly physical activity stratified by the level of each MetS components. $\mathrm{HDL}-\mathrm{C}=$ high-density lipoprotein, HTN $=$ Hypertension, MetS $=$ metabolic syndrome, $\mathrm{TG}=$ triglycerides. ${ }^{* *}$ : $p<0.01 ; *: p<0.05$; NS = not significant. (Blue column: positive for individual risk factor; Red column: negative for individual risk factor).
Table 3 Multivariate analysis of physical and biomarker risk factors for MetS among elderly male population

\begin{tabular}{llll}
\hline Factor & ORs & $\mathbf{9 5 \% ~ C l}$ & $\boldsymbol{P}$ \\
\hline BMI & 1.527 & $1.319-1.768$ & 0.001 \\
Insulin & 1.128 & $1.045-1.218$ & 0.002 \\
Physical activity & 0.997 & $0.994-0.999$ & 0.036 \\
LDL-C & 0.976 & $0.946-1.007$ & 0.132 \\
Cholesterol & 1.018 & $0.990-1.046$ & 0.210 \\
Smoking, current & 1.639 & $0.695-3.865$ & 0.259 \\
hsCRP & 1.022 & $0.965-1.082$ & 0.455 \\
Age & 1.008 & $0.954-1.064$ & 0.777 \\
\hline
\end{tabular}

Abbreviations: MetS = metabolic syndrome; ORs = odds ratios; $\mathrm{Cl}=$ confidence intervals; $\mathrm{LDL}-\mathrm{C}=$ low-density lipoprotein; hsCRP = high-sensitivity C-reactive protein.

process might be an intermittent phenomenon due to their limited physical activity.

\section{Lower HDL-C level may interact with hsCRP level in MetS} Our analytic model analyzed the interaction between individual risk components with inflammation among patients with MetS by dividing them into two groups, based on whether or not they had the existing individual MetS component. Interestingly, we found that the variation between risks of higher hsCRP was greatest within the HDL-C level, which indicated that HDL-C level might have the greatest interaction with the plasma hsCRP level in the traditional MetS risk factors. Previous report showed that physical activity is an effective way to increased human HDL-C $[29,30]$, which was also associated with hsCRP $[11,31]$. But after adjustment for physical activity, the interaction was still remained. ATP-binding membrane cassette transporter A1 (ABCA1) is a possible link between inflammation and reverse cholesterol transport [32]. The function of ABCA1 in modulating the immune response and inflammation works through its direct and indirect antiinflammatory mechanisms including lipid transport, HDL-C formation and apoptosis. These facts support the hypothesis that HDL-C may interact with plasma hsCRP through this ABCA1 pathophysiologic pathway, instead of mechanism from physical activity modulation. Compared with a previous report on a Caucasian cohort [33], this is unique and deserves an additional genetic or a larger cohort survey.

\section{Central obesity is associated with hsCRP level in MetS}

In our study cohort, once we excluded those with a waist circumference $\geq 90 \mathrm{~cm}$, there was no difference in the plasma hsCRP levels between the MetS and non-MetS groups. This analysis implied that waist circumference, or so-called "central obesity", greatly contributes to the inflammation in MetS. In this geriatric cohort, the variation in ORs from the MetS and non-MetS groups with 
a waist circumference $\geq 90 \mathrm{~cm}$ remained higher (Figure 2), which indicated that central obesity, rather than fasting glucose and triglyceride levels, might also interact with inflammation. The InCHIANTI study [33] showed that waist circumference was the major reason for elevated plasma hsCRP levels. The measurement of waist circumference is commonly recommended as a useful tool for clinically assessing visceral fat accumulation [34,35]. In our study, the median value of the hsCRP level was significantly higher in the MetS group than in the nonMetS group. However, once we excluded those without large waist circumferences, there was no significant difference in the plasma hsCRP level. This subtraction data suggested that central obesity has an important interaction with inflammation, which is indicated by a higher hsCRP level.

Plasma hsCRP levels vary between Caucasians and Asians Previous studies [36,37] have suggested hsCRP level may differ by ethnicity. Ye et al. [38] reported one median value of hsCRP level from a Chinese population 50-70 years old and living in Beijing and Shanghai to be $0.68 \mathrm{mg} / \mathrm{L}$, which was lower than the reported [39] Caucasian level. The Study of Women's Health Across the Nation [37] reported that the median values of hsCRP of Japanese and Chinese women were both also lower than the Caucasian subjects $(0.5 \mathrm{mg} / \mathrm{L}$ vs. $0.7 \mathrm{mg} / \mathrm{L}$ and $1.4 \mathrm{mg} / \mathrm{L})$. Regarding the gender comparison, the report from the Intermountain Heart Collaborative Study Group showed a significant higher mean hsCRP level was observed in American woman (woman vs. man: $1.47 \mathrm{mg} / \mathrm{dL}$ vs. $1.30 \mathrm{mg} / \mathrm{dL}, p<0.001$ ) [40]. In general, the level of hsCRP was higher in Caucasian population and also higher among the women in gender.

Our current study surveyed only gentleman within this remote geriatric community. Compared with prior younger cohort studies, our study showed a relatively higher median level of hsCRP $(1.3 \mathrm{mg} / \mathrm{L})$. The higher level of hsCRP could only partially explained by the nature aging process, because aging per se has been associated with increased inflammatory status also other degenerative disorders [41]. However, further studies comparing both genders in the same region were mandatory.

\section{MetS component distribution may vary between different cohorts}

The pathophysiological relationship between MetS and its individual components is not well understood. Traditional concepts recognize "central obesity" and "insulin resistance" as the 2 major pathogenic factors [5]. In the InCHIANTI study [33], the most common diagnostic factor was hypertension (28.1\%), followed by large waist circumference (22.8\%), high triglycerides (17.2\%), high fasting glucose (16.3\%), and low HDL-C (15.6\%). In our study, the most 2 common diagnostic factors were also hypertension (25.9\%) and a large waist circumference (21.5\%). Interestingly, our third most common MetS diagnostic factor was low HDL-C (20.6\%) rather than high triglycerides, which was the least common factor. These data also raise the consideration that various weighting ratios for individual metabolic risk components may be appropriate for different ethnic backgrounds. For example, compared with the InCHIANTI study, a lower level of HDL-C in our study seemed more important than a higher triglyceride level geriatric MetS in the Taiwanese population.

\section{Limitations}

In addition to limited number in our local community study, this unique field study remained limited because of several important confounding and study design factors. First, our study cohort enrolled only men. Whether there are significant gender differences in the pathophysiology of MetS [42] deserves additional investigation. Second, our study participants were all over 65 , so the survival effect cannot be excluded. Third, we studied only a rural population. Aekplakorn et al. [43] have shown that MetS affected both urban and rural populations with different patterns of MetS combinations. Fourth, our participants were volunteers but not randomly sampled, which might be biased because of the decreased participation rate of disabled persons. Fifth, we did not screen for their whole dietary habits. Dietary habit may be a main link the difference in prevalence of MetS between Western and Eastern countries. Interestingly, we previously reported another behavior as tea drinking to be a negative predictor for MetS [8]. Culture-associated differences in dietary and daily activity actually play important roles pathophysiologically. Finally, plasma hsCRP was examined only once in our study. It was unknown whether the hsCRP level fluctuated in that elderly population.

\section{Conclusion}

From this remote male cohort data, we demonstrated that Asian geriatric MetS had different metabolic profiles than the Caucasian populations. In addition, we concluded that different from central obesity in Caucasian cohort, the reduced physical activity was the major pathophysiological MetS factor in our Asian geriatric participants.

\section{Abbreviations}

MetS: Metabolic syndrome; haCRP: High-sensitivity C-reactive protein; ORs: Odds ratios; DM: Diabetes mellitus; IPAQ: International physical activity questionnaire; MET-hr/week: Metabolic equivalent task hours per week; NCEP-ATPIII: National cholesterol education program adult treatment panel III; HbA1C: Hemoglobin A1c; HDL-C: High-density lipoprotein; LDL-C: Low-density lipoprotein; BMI: Body mass index; SD: Standard deviation; SE: Standard error; Cl: Confidence interval; TG: Triglycerides; HTN: Hypertension; MetSC: Metabolic syndrome component.

\section{Competing interests}

All the authors declared no competing interests. 


\section{Authors' contributions}

CLC, PTL, WTC, CSC and PYL performed the survey and analyzed the data. CLC, CHW, LMT and PYL designed the study survey. CLC and PYL wrote the manuscript. JHC, LMT and PYL reviewed the manuscript. All authors read and approved the final manuscript.

\section{Acknowledgements}

We would like to thank kind collaboration by the chief leader, Dr. Chuan-Yu Chen, and all the staffs in health center of Tianliao, residency in Tianliao, and research program support (2010 and 2012) from College of Medicine, National Cheng Kung University.

\section{Author details}

'College of Medicine, National Cheng Kung University, Tainan, Taiwan. ${ }^{2}$ Division of Cardiology, Internal Medicine, National Cheng Kung University Hospital, Tainan, Taiwan. ${ }^{3}$ Institute of Clinical Medicine, National Cheng Kung University, Tainan, Taiwan. ${ }^{4}$ Internal Medicine, National Cheng Kung University Hospital Dou-Liou Branch, Yun-Lin County, Taiwan. ${ }^{5}$ Department of Family Medicine, National Cheng Kung University Hospital, Tainan, Taiwan.

Received: 12 March 2013 Accepted: 10 October 2013

Published: 14 October 2013

\section{References}

1. Reaven GM: Banting lecture 1988. Role of insulin resistance in human disease. Diabetes 1988, 37(12):1595-1607.

2. Eckel RH, Grundy SM, Zimmet PZ: The metabolic syndrome. Lancet 2005, 365(9468):1415-1428.

3. Grundy SM: Metabolic syndrome: connecting and reconciling cardiovascular and diabetes worlds. J Am Coll Cardiol 2006, 47(6):1093-1100.

4. Despres JP, Lemieux I: Abdominal obesity and metabolic syndrome. Nature 2006, 444(7121):881-887.

5. Carr DB, Utzschneider KM, Hull RL, Kodama K, Retzlaff BM, Brunzell JD, Shofer JB, Fish BE, Knopp RH, Kahn SE: Intra-abdominal fat is a major determinant of the national cholesterol education program adult treatment panel III criteria for the metabolic syndrome. Diabetes 2004, 53(8):2087-2094.

6. Gupta A, Gupta V: Metabolic syndrome: what are the risks for humans? Biosci Trends 2010, 4(5):204-212.

7. Das M, Pal S, Ghosh A: Interaction of physical activity level and metabolic syndrome among the adult Asian Indians living in Calcutta, India. J Nutr Health Aging 2012, 16(6):539-543.

8. Chang CS, Chang YF, Liu PY, Chen CY, Tsai YS, Wu CH: Smoking, habitual tea drinking and metabolic syndrome in elderly Men living in rural community: the Tianliao Old People (TOP) study 02. PLoS One 2012, 7(6):e38874.

9. Grundy SM, Brewer HB Jr, Cleeman Jl, Smith SC Jr, Lenfant C: Definition of metabolic syndrome: report of the national heart, lung, and blood institute/American heart association conference on scientific issues related to definition. Circulation 2004, 109(3):433-438.

10. Ridker PM, Wilson PW, Grundy SM: Should C-reactive protein be added to metabolic syndrome and to assessment of global cardiovascular risk? Circulation 2004, 109(23):2818-2825.

11. Mendall MA, Patel P, Ballam L, Strachan D, Northfield TC: C reactive protein and its relation to cardiovascular risk factors: a population based cross sectional study. BMJ 1996, 312(7038):1061-1065.

12. Freeman DJ, Norrie J, Caslake MJ, Gaw A, Ford I, Lowe GD, O'Reilly DS, Packard CJ, Sattar N: C-reactive protein is an independent predictor of risk for the development of diabetes in the West of Scotland coronary prevention study. Diabetes 2002, 51(5):1596-1600.

13. Onat A, Can G, Hergenc G: Serum C-reactive protein is an independent risk factor predicting cardiometabolic risk. Metabolism 2008, 57(2):207-214.

14. Pradhan AD, Manson JE, Rifai N, Buring JE, Ridker PM: C-reactive protein, interleukin 6, and risk of developing type 2 diabetes mellitus. JAMA 2001, 286(3):327-334.

15. Laaksonen DE, Niskanen L, Nyyssonen K, Punnonen K, Tuomainen TP, Valkonen VP, Salonen R, Salonen JT: C-reactive protein and the development of the metabolic syndrome and diabetes in middle-aged men. Diabetologia 2004, 47(8):1403-1410.

16. Pfutzner A, Forst T: High-sensitivity C-reactive protein as cardiovascular risk marker in patients with diabetes mellitus. Diabetes Technol Ther 2006, 8(1):28-36.

17. Brooks GC, Blaha MJ, Blumenthal RS: Relation of C-reactive protein to abdominal adiposity. Am J Cardiol 2010, 106(1):56-61.
18. Araujo JP, Lourenco P, Azevedo A, Frioes F, Rocha-Goncalves F, Ferreira A, Bettencourt P: Prognostic value of high-sensitivity C-reactive protein in heart failure: a systematic review. J Card Fail 2009, 15(3):256-266.

19. Hwang JJ, Li HY, Shieh GJ, Chien YF, Hua CH, Lin JW: Illustrating the roles of $\mathrm{C}$-reactive protein in the development of the metabolic syndrome in women-a cross-racial validation. Nutr Metab CardiovasC Dis 2008, 18(10):671-677.

20. Chien $\mathrm{KL}$, Hsu HC, Chen MF, Lee YT: Association of C-Reactive protein, smoking and metabolic syndrome among the health check-up population. Acta Cardio/ Sin 2005, 21:98-104.

21. Golbidi S, Mesdaghinia A, Laher I: Exercise in the metabolic syndrome. Oxid Med Cell Longev 2012, 2012:349710.

22. Geffken DF, Cushman M, Burke GL, Polak JF, Sakkinen PA, Tracy RP: Association between physical activity and markers of inflammation in a healthy elderly population. Am J Epidemiol 2001, 153(3):242-250.

23. Kaohsiung County Tianliao Township Household Registration Affairs [In Chinese]. http://tianliaohouse.gov.tw/en/en_index.php.

24. Craig $C L$, Marshall AL, Sjostrom $M$, Bauman AE, Booth ML, Ainsworth BE, Pratt $M$, Ekelund U, Yngve A, Sallis JF, et al: International physical activity questionnaire: 12-country reliability and validity. Med Sci Sports Exerc 2003, 35(8):1381-1395.

25. Grundy SM, Cleeman JI, Daniels SR, Donato KA, Eckel RH, Franklin BA, Gordon DJ, Krauss RM, Savage PJ, Smith SC Jr, et al: Diagnosis and management of the metabolic syndrome: an American heart association/national heart, lung, and blood institute scientific statement. Circulation 2005, 112(17):2735-2752.

26. American Diabetes Association: Standards of medical care in diabetes--2010. Diabetes Care 2010, 33(Suppl 1):S11-61.

27. Pearson TA, Mensah GA, Alexander RW, Anderson JL, Cannon RO 3rd, Criqui M, Fadl YY, Fortmann SP, Hong Y, Myers GL, et al: Markers of inflammation and cardiovascular disease: application to clinical and public health practice: a statement for healthcare professionals from the centers for disease control and prevention and the American heart association. Circulation 2003, 107(3):499-511.

28. Tournoy J, Lee DM, Pendleton N, O'Neill TW, O'Connor DB, Bartfai G, Casanueva FF, Finn JD, Forti G, Giwercman A, et al: Association of cognitive performance with the metabolic syndrome and with glycaemia in middle-aged and older European men: the European male ageing study. Diabetes Metab Res Rev 2010, 26(8):668-676.

29. Dai DF, Hwang JJ, Chen CL, Chiang FT, Lin JL, Hsu KL, Tseng CD, Tseng YZ: Effect of physical activity on the prevalence of metabolic syndrome and left ventricular hypertrophy in apparently healthy adults. J Formos Med Assoc 2010, 109(10):716-724

30. Koba S, Tanaka H, Maruyama C, Tada N, Birou S, Teramoto T, Sasaki J: Physical activity in the Japan population: association with blood lipid levels and effects in reducing cardiovascular and all-cause mortality. J Atheroscler Thromb 2011, 18(10):833-845.

31. Hu M, Lee MH, Mak VW, Tomlinson B: Effect of central obesity, low high-density lipoprotein cholesterol and C-reactive protein polymorphisms on C-reactive protein levels during treatment with Rosuvastatin (10 mg Daily). Am J Cardio/ 2010, 106(11):1588-1593.

32. Yin K, Liao DF, Tang CK: ATP-binding membrane cassette transporter A1 ( $A B C A 1)$ : a possible link between inflammation and reverse cholesterol transport. Mol Med 2010, 16(9-10):438-449.

33. Zuliani G, Volpato S, Galvani M, Ble A, Bandinelli S, Corsi AM, Lauretani F, Maggio M, Guralnik JM, Fellin R, et al: Elevated C-reactive protein levels and metabolic syndrome in the elderly: The role of central obesity data from the InChianti study. Atherosclerosis 2009, 203(2):626-632.

34. Ferland M, Despres JP, Tremblay A, Pinault S, Nadeau A, Moorjani S, Lupien PJ, Theriault G, Bouchard C: Assessment of adipose tissue distribution by computed axial tomography in obese women: association with body density and anthropometric measurements. Br J Nutr 1989, 61(2):139-148.

35. Pouliot MC, Despres JP, Lemieux S, Moorjani S, Bouchard C, Tremblay A, Nadeau A, Lupien PJ: Waist circumference and abdominal sagittal diameter: best simple anthropometric indexes of abdominal visceral adipose tissue accumulation and related cardiovascular risk in men and women. Am J Cardiol 1994, 73(7):460-468.

36. Anand SS, Razak F, Yi Q, Davis B, Jacobs R, Vuksan V, Lonn E, Teo K, McQueen M, Yusuf S: C-reactive protein as a screening test for cardiovascular risk in a multiethnic population. Arterioscler Thromb VasC Biol 2004, 24(8):1509-1515. 
37. Matthews KA, Sowers MF, Derby CA, Stein E, Miracle-McMahill H, Crawford $\mathrm{SL}$, Pasternak RC: Ethnic differences in cardiovascular risk factor burden among middle-aged women: study of women's health across the nation (SWAN). Am Heart J 2005, 149(6):1066-1073.

38. Ye X, Yu Z, Li H, Franco OH, Liu Y, Lin X: Distributions of C-reactive protein and its association with metabolic syndrome in middle-aged and older Chinese people. J Am Coll Cardiol 2007, 49(17):1798-1805.

39. Hubacek JA, Skodova Z, Lanska V, Stavek P, Adamkova V, Poledne R: Apolipoprotein AV variants do not affect C-reactive protein levels in caucasian males. Physiol Res 2005, 54(6):687-689.

40. Khor LL, Muhlestein JB, Carlquist JF, Horne BD, Bair TL, Maycock CA, Anderson $J$ : Sex- and age-related differences in the prognostic value of C-reactive protein in patients with angiographic coronary artery disease. Am J Med 2004, 117(9):657-664.

41. Howcroft TK, Campisi J, Louis GB, Smith MT, Wise B, Wyss-Coray T, Augustine AD, McElhaney JE, Kohanski R, Sierra F: The role of inflammation in age-related disease. Aging (Albany NY) 2013, 5(1):84-93.

42. Iyer A, Kauter K, Brown L: Gender differences in metabolic syndrome - a Key research issue? Endocr Metab Immune Disord Drug Targets 2011, 11(3):182-188.

43. Aekplakorn W, Kessomboon P, Sangthong R, Chariyalertsak S, Putwatana P, Inthawong R, Nitiyanant W, Taneepanichskul S: Urban and rural variation in clustering of metabolic syndrome components in the Thai population: results from the fourth national health examination survey 2009. BMC Public Health 2011, 11(1):854.

doi:10.1186/1758-5996-5-60

Cite this article as: Chang et al:: The interplay between inflammation, physical activity and metabolic syndrome in a remote male geriatric community in Southern Taiwan: the Tianliao Old People (TOP) study 03. Diabetology \& Metabolic Syndrome 2013 5:60

\section{Submit your next manuscript to BioMed Central and take full advantage of:}

- Convenient online submission

- Thorough peer review

- No space constraints or color figure charges

- Immediate publication on acceptance

- Inclusion in PubMed, CAS, Scopus and Google Scholar

- Research which is freely available for redistribution 